\title{
Metabolic effects of hydrophobic alginate derivative and tetrahydrolipstatin in rats fed diet supplemented with palm fat and cholesterol
}

\author{
Milan Marounek ${ }^{1,2, *}$, Zdeněk Volek ${ }^{1,2}$, Tomáš Taubner ${ }^{1}$, Dagmar Dušková ${ }^{1}$, Marian Czauderna ${ }^{3}$ \\ ${ }^{1}$ Department of Nutrition Physiology and Animal Product Quality, Institute of Animal Science, CZ-104 00, Praha- \\ Uhríněves, Czech Republic
}

2 Department of Microbiology, Nutrition and Dietetics, Faculty of Agrobiology, Food and Natural Resources, Czech University of Life Sciences, CZ-165 00, Prague, Czech Republic

${ }^{3}$ The Kielanowski Institute of Animal Physiology and Nutrition, Polish Academy of Sciences, 05-110 Jablonna, Poland

*Correspondence: marounek.milan@vuzv.cz; Tel.: +420 776053 360; Fax: +420 267710779

\begin{abstract}
The effects of octadecylamide of alginic acid (amidated alginate) and tetrahydrolipstatin on serum and hepatic cholesterol, and the faecal output of fat and sterols were compared in rats. Amidated alginate is a sorbent of lipids, tetrahydrolipstatin is inhibitor of pancreatic lipase. Rats were fed diets containing cholesterol and palm fat at 10 and $70 \mathrm{~g} / \mathrm{kg}$, respectively. Palm fat was provided by coconut meal. Amidated alginate at $40 \mathrm{~g} / \mathrm{kg}$ diet significantly decreased serum total cholesterol, LDL and hepatic cholesterol, hepatic lipids, and increased faecal output of fat and coprostanol. Tetrahydrolipstatin at 300 $\mathrm{mg} / \mathrm{kg}$ diet significantly decreased LDL cholesterol, hepatic lipids and increased faecal output of fat. The intake of feed was not significantly influenced, however the weight gains in rats fed amidated alginate was lower than in rats of the control group. Both amidated alginate and tetrahydrolipstatin modified fatty acid profile in excreta lipids. Concentrations of saturated fatty acids were decreased and that of unsaturated fatty acids were increased. Despite different mode of action, amidated alginate and tetrahydrolipstatin were equally efficient in the removing dietary fat from the body.
\end{abstract}

Keywords: amidated alginate; tetrahydrolipstatin; cholesterol; rats; serum; liver 


\section{Introduction}

Overweight is the risk factor for covid-19 and several chronic diseases (coronary heart disease, cancer, hypertension, diabetes type 2). Classical treatments for overweight such as dieting, behavioural modification and exercise, often fail; thus, there is the need for drugs and agents efficient in the treatment of overweight. New drugs are inhibitors of food intake which reduce hunger perception, inhibitors of nutrient absorption, and drugs, which increase energy expenditure [1]. Tetrahydrolipstatin (THL), commercially available as Xenical and Orlistat, is an inhibitor of pancreatic lipase with little or no activity against amylase, trypsin, chymotrypsin and phospholipases [2]. Orlistat, a semisynthetic derivative of lipstatin, partially inhibits hydrolysis of triglycerides, thus decreases the subsequent absorption of monoglycerides and free fatty acids. THL inhibits hydrolysis of triglycerides, but does not interfere with the absorption of the hydrolysis products if present in the feed [3]. Orlistat has been shown to decrease the absorption of lipophilic micronutrients in rats [4], and decreases the absorption of vitamin $E$ in healthy volunteers [5]. The alterntives to drugs are herbal preparations that regulate lipid metabolism [6] and decrease weight gain [7]. Soluble fibres (psyllium and gel-forming polysaccharides) increase intestinal viscosity and affect the process of digestion and absorption. Tsujita et al. [8] and Edashige et al. [9], showed that citrus pectin inhibited pancreatic lipase. Alginate, a copolymer of $\beta$-D-mannuronate and $\alpha$-Lguluronate also inhibited the activity of pancreatic lipase. The degree of inhibition depended on the mannuronate and guluronate ratio. High guluronate alginate inhibited lipase to a higher degree than high mannuronate alginate [10]. The physiological effects of alginate and pectin are similar as both polysaccharides are polymers of uronic acids. Converting hydrophilic pectin or alginate to their hydrophobic derivatives (amidated pectin and amidated alginate) significantly increased in rats the concentration of fat in excreta and faecal cholesterol concentrations [11, 12].

In rats fed high fat diet containing corn oil THL at $200 \mathrm{mg} / \mathrm{kg}$ significantly decreased serum concentration of triglycerides, total and LDL cholesterol, but increased concentration of HDL cholesterol [7]. The authors, however, did not measured faecal concentration of fat, cholesterol and daily faecal 
output of fat and sterols. The information about the effect of diets on the fatty acid profile of faecal lipids is absent in the available literature. Thus, the aim of the present study was to compare the effect of THL and amidated alginate on the faecal output of fat, sterols, and fatty acid profile of faecal lipids in rats fed a diet supplemented with cholesterol and palm fat. We tested a hypothesis that the effects of amidated alginate and THL may be similar despite different mode of action. The alginate obtained from the supplier and amidated alginates were characterized in order to obtain information which may be important in the present experiment.

\section{Experimental}

\subsection{Animals and diets}

Twenty-one female Wistar rats, approximately 6-weeks-old, were used. The rats were housed individually in a temperature- and humidity-controlled room. The vivarium was maintained on a $12 \mathrm{~h}$ light: $12 \mathrm{~h}$ dark daily photoperiod cycle at a temperature of $22 \pm 1{ }^{\circ} \mathrm{C}$. All diets were supplemented with cholesterol at 10 $\mathrm{g} / \mathrm{kg}$, and with coconut meal at $124 \mathrm{~g} / \mathrm{kg}$. The coconut meal containing $56.5 \%$ fat was purchased in a local shop with healthy food. Diets contained $10.9 \%$ of fat, including cholesterol. After 4 weeks of adaptation of rats to new environment, the rats were randomly divided into three groups of 7 rats each. 
Table 1. Composition of control and experimental diets $(\mathrm{g} / \mathrm{kg})$

\begin{tabular}{|c|c|c|c|}
\hline Diet & $1^{\mathrm{a}}$ & 2 & 3 \\
\hline Cholesterol (g/kg) & 10 & 10 & 10 \\
\hline Palm fat ${ }^{\mathrm{b}}(\mathrm{g} / \mathrm{kg})$ & 124 & 124 & 124 \\
\hline Amidated alginate (g/kg) & - & 40 & - \\
\hline Tetrahydrolipstatin $(\mathrm{mg} / \mathrm{kg}$ ) & - & - & 300 \\
\hline Cellulose (g/kg) & 40 & - & 40 \\
\hline Diet ST-1 ${ }^{\mathrm{C}}(\mathrm{g} / \mathrm{kg})$ & 866 & 866 & 866 \\
\hline
\end{tabular}

${ }^{\mathrm{a}}$ Control diet, ${ }^{\mathrm{b}}$ Coconut meal containing $56.5 \%$ fat, ${ }^{\mathrm{c}}$ The rat diet ingredients were soybean meal, meat and bone meal, cereals, wheat bran, limestone, dicalcium phosphate, salt, and supplements vitamins, trace elements and amino acids. The diet ST-1 contained crude protein, fibre, fat, ash and cholesterol at $224,45,33,43$ and $0.29 \mathrm{~g} / \mathrm{kg}$, respectively.

Table 1 presents composition of control and experimental diets. The rat diet ST-1 was supplied by Velaz Ltd. (Lysolaje, Czech Republic). Diet no.1 (control diet) was without additives. Diet no. 2 was supplemented with amidated alginate at $40 \mathrm{~g} / \mathrm{kg}$, at the expense of cellulose. A dose-response study was performed in which diets of rats were supplemented with amidated alginate at 0,20 and $40 \mathrm{~g} / \mathrm{kg}$. The intake of feed and weight gain were not significantly affected [13]. The diet no. 2 was thus used in the following experiment. Diet no. 3 was supplemented with THL at $300 \mathrm{mg} / \mathrm{kg}$. This dosing is the average of Orlistat concentrations used in the experiment of Cruz-Hernandez et al. [4]. Diets and water were available ad libitum. In the course of this experiment, feed intake, initial and final body weights were measured (Table 2). The study was approved by the Ethics Committee of the Institute of Animal Science and the Central Commission for Animal Welfare of the Ministry of Agriculture of the Czech Republic. 
Table 2. Effect of diets on initial weight, final weight, weight gain and daily feed intake of rats (g)

\begin{tabular}{lccc}
\hline Diet & $\mathbf{1}$ & $\mathbf{2}$ & $\mathbf{3}$ \\
\hline Initial weight & $240 \pm 29$ & $237 \pm 28$ & $239 \pm 28$ \\
Final weight & $286 \pm 31$ & $262 \pm 28$ & $269 \pm 27$ \\
Weight gain & $46 \pm 14^{\mathrm{a}}$ & $25 \pm 10^{\mathrm{b}}$ & $30 \pm 18^{\mathrm{ab}}$ \\
Feed intake & $19 \pm 1.6$ & $17 \pm 2.0$ & $19 \pm 1.0$ \\
\hline
\end{tabular}

${ }^{a-b}$ Values in the same row with different superscripts differ significantly $(p<0.05)$

The experiment duration was 3 weeks, and then, the rats were sacrificed by decapitation after anaesthesia by the inhalation of isoflurane (Nicholas Piramal India Ltd., London, U.K.). The rats received 4 $\mathrm{g}$ of feed $4 \mathrm{~h}$ before they were sacrificed [14].

\subsection{Materials and reagents}

The sodium salt of alginic acid, a low-viscosity product A1112, from brown algae, was obtained in a dry powder form from Sigma-Aldrich (Prague, Czech Republic). THL (Orlistat), a certified reference material (PHR 1445), microcrystalline cellulose and $n$-octadecylamine were purchased from Sigma-Aldrich. $\mathrm{N}, \mathrm{N}$-dimethylformamide, ethanol, methanol, petrolether, hydrochloric acid, sulphuric acid and acetone were purchased from P-Lab (Prague, Czech Republic). For analytical methods we used formamide, sodium hydroxide, 3,5-dinitrosalicylic acid, potassium sodium tartrate, calcium acetate, and phenolphthalein purchased from P-Lab. D-mannuronic acid sodium and agent 1-phenyl-3-methyl-5-pyrazolone (PMP) were purchased from Sigma-Aldrich (Prague), L-guluronic acid sodium was obtained from Carbosynth Ltd., Compton, U.K. The Sylon HTP kit (hexamethyldisilazane-trimethylchlorsilan-pyridine 3:1:9) was purchased from Supelco (Bellefonte, U.S.A.). Isolithocholic acid, 12-ketolithocholic acid, norcholic acid, $\alpha-, \beta-, \omega$ muricholic acids, and $\beta$-sitostanol were purchased from Steraloids Inc. (Newport, U.S.A.). Other sterols were supplied by Sigma-Aldrich (Prague).

\subsection{Preparation of amidated alginate}


Alginic acid was prepared by washing the sodium alginate with acidified ethanol, pure ethanol and acetone, followed by air drying. Alginic acid was esterified with methanol in the presence of sulfuric acid. The solid reaction product was filtered, washed with ethanol and acetone, and then dried in air. The methyl ester was amino-dealkoxylated with n-octadecylamine [15].

\subsection{Analytical methods}

\subsubsection{Carboxyl groups assay and determination of degree of amidation}

The content of all carboxyl groups $\mathrm{COOH}_{\mathrm{t}}(\% \mathrm{~m} / \mathrm{m})$ in alginic acid and the content of free carboxyl groups $\mathrm{COOH}_{\mathrm{f}}(\% \mathrm{~m} / \mathrm{m})$ in its methyl ester were determined by a titration method and calculated as described by Taubner et al. [15]. The degree of amidation (DA, mol. \%) of the final products was calculated based on the carbon $(C)$ and nitrogen $(N)$ content $(\% \mathrm{~m} / \mathrm{m})$. See the previous report [16] for details.

\subsubsection{Molecular weight assay}

The reaction with organic dinitroderivatives is based on the ability to reduce dinitrosalicylic acid by reducing polysaccharide groups [17]. The colour intensity was measured using a spectrophotometer at a wavelength of $545 \mathrm{~nm}$. Galacturonic acid was used for the calibration. The degree of polymerization and molecular weight were calculated from the absorbance of the polysaccharide sample.

\subsubsection{Analysis of mannuronic to galacturonic acid ratio in alginate}

Alginate was hydrolysed using trifluoracetic acid as described by Wang et al. [18], with some modifications. The pre-column derivatization of uronic acids with 1-phenyl-3-methyl-5-pyrazolone and HPLC analysis were performed as described by Wu et al. [19] with some modifications. The same procedure was used to treat monosaccharide standards and their equimolar mixture. The analytical C18- 
column ( $250 \times 4.6 \mathrm{~mm}, 5 \mu \mathrm{m}$, ZORBAX, Agilent Company) was used at a temperature of $30^{\circ} \mathrm{C}$. The elution of derivatized monosaccharides was performed with a mixture of $0.1 \mathrm{M}$ phosphate buffer ( $\mathrm{pH}$ 6.7) and acetonitrile The UV absorbance of the effluent was monitored at $245 \mathrm{~nm}$. Guluronate and mannuronate peaks were identified on basis of the retention times of standards. Mannuronate to guluronate ratio was calculated from the ratio of peaks area corrected for the ratio of response factors.

\subsubsection{Sampling}

Mixed blood samples were collected from each rat at the time of euthanasia. The sera were separated by centrifugation and analysed the subsequent day. The livers were excised and kept at $-40{ }^{\circ} \mathrm{C}$ until analysis. Faeces were collected during the last 5 days of the experiment, weighed, pooled and stored frozen until analysis. Analyses of hepatic and faecal lipids (fat, fatty acids and sterols) were performed as described previously [13]. Faecal samples for analyses of sterols and fatty acid profile were freeze-dried. The serum cholesterol, triacylglycerols, bilirubin, aminotransferases AST and ALT were determined using kits BioVendor Ltd. (Brno, Czech Republic).

\subsubsection{Other analyses}

The fatty acid (FA) profile of coconut meal, fat content in coconut meal, and analyses of ST-1 diet were performed as described by the previous study [20]. Triacylglycerols in coconut meal were determined as described by Kobayashi et al. [21]. Lipids were dissolved in hexane, insoluble particles removed by centrifugation, and supernatant injected onto the Luna $3 \mu \mathrm{m}$ C18 (2)100 Å, LC column for separation of hydrophobic compounds (Phenomenex, Torrance, U.S.A.). A HPLC system Shimadzu (Japan) incorporating a guard column and evaporative light scattering detector was employed. The system consisted of following components: a model LC-20AD pump, a model column oven CTO-20AC, a model ELSD-LT detector, a model HPLC communication interface CBM-20A, a model auto injector SIL-20AC, a model degasser DGU-20A5. A gradient program based on two solvents was used: The first solvent consisted of $98.9 \%$ hexane, $1 \%$ isopropanol and $0.1 \%$ acetic acid. The second solvent contained $99.9 \%$ 
isopropanol and $0.1 \%$ acetic acid. The method was calibrated with glyceryl tripalmitate dissolved in hexane.

\subsection{Statistics}

The data were analysed by a one-way analysis of variance using the GLM procedure of SAS, version 8.2 (SAS Institute, Cary, NC, U.S.A.). The results were expressed as the mean and the standard deviation. Significant differences $(p<0.05)$ were identified using Tukey's test. The Pearson correlation coefficient was used as a measure of the dependence between pairs of observations.

\section{Results}

Average initial and final body weights of rats were $238.7 \mathrm{~g}$ and $272.3 \mathrm{~g}$, respectively. Body weights of rats and the feed intake did not differ among treatment groups. Weight gain of rats fed amidated alginate was significantly lower than that of control rats (Table 2).

\subsection{Characterization of alginate and amidated alginate}

Table 3 presents characteristics of alginate, its methylester and amidated alginate prepared from alginate of low viscosity. Molecular weight of low-viscosity alginate was $58.9 \mathrm{~kg} / \mathrm{mol}$. After methylation and amidation molecular weight of final product was decreased to $12.3 \mathrm{~kg} / \mathrm{mol}$. Average value of mannuronate/guluronate ratio calculated from results of three analyses carried out at different days was $2.65 \pm 0.05$ 
Table 3. Characterization of alginate, methylester of alginic acid, and amidated alginate

\begin{tabular}{|c|c|c|c|}
\hline & Na-alginate & & $\mathrm{H}$-alginate \\
\hline Content of uronic acids $(\% \mathrm{~m} / \mathrm{m})$ & 72.2 & & 74.5 \\
\hline Mannuronate/guluronate $(\mathrm{m} / \mathrm{m})$ & & 2.65 & \\
\hline Molecular weight $(\mathrm{kg} / \mathrm{mol})$ & 58.9 & & 43.9 \\
\hline \multicolumn{4}{|l|}{ Methylester of alginate } \\
\hline Degree of methylation (mol. \%) & & 66.7 & \\
\hline Molecular weight (kg/mol) & & 15.9 & \\
\hline \multicolumn{4}{|l|}{ Amidated alginate } \\
\hline Degree of amidation (mol. \%) & & 77.7 & \\
\hline Molecular weight (kg/mol) & & 12.3 & \\
\hline
\end{tabular}

\subsection{Characterization of palm fat and coconut meal}

In coconut meal the main fatty acid was myristic acid followed by palmitic acid and capric acid. Oleic was the main unsaturated FA present in coconut meal (Table 4). Coconut meal contained $56.5 \%$ fat determined by extraction with petroleum ether. The HPLC analysis showed that coconut meal contained triacylglycerols expressed as tripalmitin at $623 \mathrm{mg} / \mathrm{g}$.

Table 4. Fatty acid profile of coconut meal (g per $100 \mathrm{~g}$ fatty acids determined)

\begin{tabular}{lcc}
\hline Fatty acid & & Coconut meal \\
\hline Caproic & C 6:0 & 1.14 \\
Caprylic & C 8:0 & 6.55 \\
Capric & C 10:0 & 13.48 \\
Lauric & C 12:0 & 8.62 \\
Myristic & C 14:0 & 30.53 \\
Palmitic & C 16:0 & 19.21 \\
Stearic & C 18:0 & 7.33 \\
Oleic & C 18:1c9 & 9.42 \\
\hline
\end{tabular}




\begin{tabular}{lcc}
\hline Elaidic & C 18:1t9 & 0.10 \\
Linoleic & C 18:2 & 2.13 \\
\hline
\end{tabular}

In total 35 fatty acids were assayed.

\subsection{Effects of amidated alginate and tetrahydrolipstatin on serum and hepatic parameters and faecal} output of fat and sterols in rats

Supplementation of the diet with amidated alginate and THL significantly decreased serum total cholesterol, serum LDL cholesterol, cholesterol concentration in the liver tissue and concentration of hepatic lipids. The concentration of serum bilirubin and activities of aminotransferases were not significantly affected (Table 5). The serum triacylglycerols correlated significantly with serum cholesterol $(r=0.610 ; p=0.003)$, and non-significantly with total hepatic lipids $(r=0.378, p=0.091)$. Serum cholesterol correlated significantly with hepatic cholesterol $\left(r=0.804, p<10^{-4}\right)$. Daily faecal output of fat was significantly increased in rats fed diets supplemented with amidated alginate and THL. Amidated alginate significantly increased the faecal loss of coprostanol and total neutral sterols. Bile acids output, serum concentration of bilirubin, and activity of aminotransferases were not significantly influenced.

Table 5. Effect of amidated alginate and tetrahydrolipstatin $(\mathrm{g} / \mathrm{kg})$ on serum and hepatic parameters and faecal output of sterols in rats fed diets 1, 2, 3 .

\begin{tabular}{lccc}
\hline Diet & $\mathbf{1}$ & $\mathbf{2}$ & $\mathbf{3}$ \\
Amidated alginate $(\mathrm{g} / \mathrm{kg})$ & - & 40 & - \\
Tetrahydrolipstatin $(\mathrm{mg} / \mathrm{kg})$ & - & - & 300 \\
\hline Serum concentrations & & & \\
Total cholesterol $(\mu \mathrm{mol} / \mathrm{mL})$ & $3.89 \pm 0.29^{\mathrm{a}}$ & $1.75 \pm 0.21^{\mathrm{b}}$ & $2.75 \pm 0.90^{\mathrm{ab}}$ \\
LDL cholesterol $(\mu \mathrm{mol} / \mathrm{mL})$ & $1.92 \pm 0.20^{\mathrm{a}}$ & $0.79 \pm 0.11^{\mathrm{b}}$ & $1.28 \pm 0.54^{\mathrm{c}}$ \\
Triacylglycerols $(\mu \mathrm{mol} / \mathrm{mL})$ & $2.67 \pm 1.53$ & $1.13 \pm 0.61$ & $1.71 \pm 1.52$ \\
ALT $(\mathrm{nkat} / \mathrm{mL})$ & $1.24 \pm 0.32$ & $1.43 \pm 0.50$ & $1.53 \pm 0.72$
\end{tabular}



AST (nkat/mL)
$4.22 \pm 1.26$
$3.82 \pm 1.18$
$6.10 \pm 3.26$
Bilirubin $(\mu \mathrm{mol} / \mathrm{mL})$
$2.79 \pm 0.20$
$2.71 \pm 0.51$
$2.70 \pm 0.32$

Hepatic parameters

Hepatic cholesterol ( $\mu \mathrm{mol} / \mathrm{g}$ )

$37.14 \pm 8.75^{\mathrm{a}}$

$7.00 \pm 0.61^{b}$

$23.17 \pm 3.66^{c}$

Hepatic lipids (mg/g)

$102.4 \pm 15.7^{\mathrm{a}}$

$46.3 \pm 5.1^{\mathrm{b}}$

$80.9 \pm 4.9^{c}$

Daily faecal output

Dry matter (g)

$5.20 \pm 0.72^{\mathrm{ac}}$

$5.98 \pm 0.62^{\mathrm{a}}$

$4.60 \pm 0.62^{\circ}$

Fat (g)

$0.42 \pm 0.07^{\mathrm{a}}$

$0.97 \pm 0.11^{\mathrm{b}}$

$1.00 \pm 0.16^{b}$

Cholesterol ( $\mu \mathrm{mol})$

$481 \pm 84$

$569 \pm 53$

$581 \pm 80$

Coprostanol ( $\mu \mathrm{mol})$

$166 \pm 49^{a}$

$245 \pm 59^{b}$

$146 \pm 52^{a}$

Neutral sterols ${ }^{d}(\mu \mathrm{mol})$

$750 \pm 126^{a}$

$908 \pm 67^{b}$

$851 \pm 140^{\text {ab }}$

Bile acids ( $\mu \mathrm{mol})$

$137 \pm 22$

$104 \pm 28$

$114 \pm 30$

Total sterols ( $\mu \mathrm{mol})$

$887 \pm 132$

$1012 \pm 89$

$965 \pm 151$

Seven rats per group. All diets contained cholesterol and coconut meal. ${ }^{\text {a-c }}$ Values in the same row with different superscripts differ significantly $(p<0.05) .{ }^{d}$ Including plant sterols

Amidated alginate and THL modified fatty acid profile in excreta lipids. Concentration of saturated fatty acids was decreased and that of unsaturated fatty acids was increased (Table 6).

Table 6. Fatty acid profile ${ }^{a}$ in excreta of rats fed control diet and diets supplemented with amidated alginate and tetrahydrolipstatin $(\mathrm{g} / \mathrm{kg})$

\begin{tabular}{lccc}
\hline Diet & $\mathbf{1}$ & $\mathbf{2}$ & $\mathbf{3}$ \\
Amidated alginate $(\mathrm{g} / \mathrm{kg})$ & - & 40 & - \\
Tetrahydrolipstatin $(\mathrm{mg} / \mathrm{kg})$ & - & - & 300 \\
\hline Caproic & 0 & 0 & $0.40 \pm 0.12$ \\
Caprylic & $1.38 \pm 0.22^{\mathrm{b}}$ & $0.57 \pm 0.13^{\mathrm{c}}$ & $7.64 \pm 0.88^{\mathrm{d}}$ \\
Capric & $1.88 \pm 0.41^{\mathrm{b}}$ & $0.67 \pm 0.22^{\mathrm{c}}$ & $6.84 \pm 0.45^{\mathrm{d}}$ \\
\hline
\end{tabular}




\begin{tabular}{lccc}
\hline Lauric & $29.21 \pm 1.67^{\mathrm{b}}$ & $16.07 \pm 5.80^{\mathrm{c}}$ & $18.20 \pm 1.83^{\mathrm{c}}$ \\
Myristic & $20.75 \pm 0.87^{\mathrm{b}}$ & $14.56 \pm 4.57^{\mathrm{c}}$ & $23.31 \pm 1.20^{\mathrm{b}}$ \\
Palmitic & $16.36 \pm 0.56^{\mathrm{b}}$ & $22.10 \pm 2.53^{\mathrm{c}}$ & $14.08 \pm 0.34^{\mathrm{d}}$ \\
Stearic & $7.13 \pm 1.38^{\mathrm{b}}$ & $19.78 \pm 7.17^{\mathrm{c}}$ & $5.88 \pm 0.68^{\mathrm{b}}$ \\
Oleic & $4.82 \pm 0.36^{\mathrm{b}}$ & $5.63 \pm 0.93^{\mathrm{b}}$ & $8.64 \pm 0.43^{\mathrm{c}}$ \\
Elaidic & $1.16 \pm 0.31^{\mathrm{b}}$ & $2.72 \pm 0.65^{\mathrm{c}}$ & $0.70 \pm 0.23^{\mathrm{b}}$ \\
Linoleic & $7.02 \pm 1.43^{\mathrm{b}}$ & $6.39 \pm 1.66^{\mathrm{b}}$ & $9.59 \pm 0.59^{\mathrm{c}}$ \\
Saturated FA & $85.95 \pm 1.89^{\mathrm{b}}$ & $77.73 \pm 2.68^{\mathrm{c}}$ & $80.12 \pm 1.35^{\mathrm{c}}$ \\
Monounsaturated FA & $6.6 \pm 0.65^{\mathrm{b}}$ & $8.60 \pm 1.07^{\mathrm{c}}$ & $9.51 \pm 0.55^{\mathrm{c}}$ \\
Polyunsaturated FA & $7.37 \pm 0.49^{\mathrm{b}}$ & $13.67 \pm 1.87^{\mathrm{c}}$ & $10.23 \pm 0.66^{\mathrm{bc}}$ \\
\hline
\end{tabular}

${ }^{a} \mathrm{~g}$ per $100 \mathrm{~g}$ of fatty acids determined. ${ }^{\mathrm{b}-\mathrm{d}}$ Values in the same row with different superscripts differ significantly $(p<0.05)$

\section{Discussion}

In the present experiment, a diet supplemented with palm fat and cholesterol was used. Contrary to our previous experiments $[12,13]$, coconut meal containing $56.5 \%$ fat and triacylglycerols at $623 \mathrm{mg} / \mathrm{g}$ was used instead of palm fat AkoFeed Gigant 60. Dosing of amidated alginate $(40 \mathrm{~g} / \mathrm{kg})$ has already been used previously [13]. Dosing of THL (Orlistat) was $3.75 \mathrm{mg} / \mathrm{g}$ fat, which was in the range of concentrations tested by Ackroff and Sclafani [22]. Both aditives are safe. Neither amidated alginate nor THL negatively influenced parameters of hepatocellular health (serum bilirubin, ALT, AST). The EFSA panel "Food Additives Nutrient" concluded that there is no safety concern for the use of pectin and amidated pectin for the general population and that there is no need for "Acceptable daily intake" [23].

Alginate is a natural polysaccharide, the composition of which depends on the algae species. The molecular weight and the mannuronate to guluronate ratio play a significant role in the alginate's physicochemical properties [24]. During the amidated alginate synthesis acid hydrolysis conditions caused reduction of the average molecular weight. In the experiment of Sánchez-Machado et al. [25], the 
mannuronate to guluronate ratio of five seaweed species varied from 2.3 to 4.3 . Our findings ( 2.6 and 2.8 ) were thus in this range.

Modified polysaccharides containing long hydrocarbon chains are efficient sorbents of lipids, as shown in experiments with amidated pectin [26], amidated celluloses [27], and amidated alginate [12]. In the present experiment, in rats fed amidated alginate serum and hepatic cholesterol concentrations were decreased and faecal outputs of fat and coprostanol (metabolite of cholesterol) were increased. The loss of energy in faeces was probably the main reason of lower weight gain in rats fed amidated alginate. The low concentration of hepatic cholesterol may be the reason of the low faecal output of bile acids in rats. Bile acid synthesis in rat hepatocytes may be regulated by the availability of cholesterol for cholesterol 7a-hydroxylase [28].

Amidated alginate and THL increased the faecal loss of fat, the mode of action of both agents, however was different. Amidated alginate is a non-specific sorbent of lipids, THL inhibits triacylglycerol hydrolysis which is the prerequisite of the lipid absorption. Both amidated alginate and THL decreased concentration of saturated fatty acids in excreta of rats and increased concentration of monounsaturated and polyunsaturated fatty acids. This may be related to the fact that unsaturated lipids are more easily incorporated into mixed micelles in the intestine. It is possible, however, that in amidated alginate-fed rats also lipophilic vitamins may be partially lost in faeces.

It follows from data in Table 5 that amidated alginate and THL were equally efficient in the removal of dietary fat from the body. Hydrolysis of cholesterol esters is necessary for cholesterol absorption. Data on the effect of THL on the activity of intestinal cholesterol esterase are lacking in the literature.

\section{Acknowledgements}

This work was supported by the Ministry of Agriculture of the Czech Republic (Project MZERO0718). 


\section{References}

1. Alemany, M.; Remesar, X.; Fernández-López, J.A. Drug strategies for the treatment of obesity. IDrugs 2003, 6, 566-572.

2. Guerciolini, R. Mode of action of orlistat. Int. J. Obesity 1997, 21, S12-S23.

3. Porsgaard, T.; Straarup, E.M.; Mu, H.L.; Høy, C.E. Effect of orlistat on fat absorption in rats: A comparison of normal rats and rats with diverted bile and pancreatic juice. Lipids 2003, 38, 10391043.

4. Cruz-Hernandez, C.; Oliveira, M.; Pescia, G.; J. Moulin, J.; Masserey-Elmelegy, I.; Dionisi, F.; Destaillats, F. Lipase inhibitor orlistat decreases incorporation of eicosapentaenoic and docosahexaenoic acids in rat tissues. Nutr. Res. 2010, 30, 134-140.

5. Melia, A.T.; KossTwardy, S.G.; Zhi, J.G. The effect of orlistat, an inhibitor of dietary fat absorption, on the absorption of vitamins A and E in healthy volunteers. J. Clin. Pharmacol. 1996, 36, 647-653.

6. Lee, Y.H.; Jin, B.; Lee, S.H.; Song, M.; Bae, H.; Min, B.J.; Park, J.; Lee, D.; Kim, H. Herbal formula HT048 attenuates diet-induced obesity by improving hepatic lipid metabolism and insulin resistance in obese rats. Molecules 2016, 21, article no. 1424.

7. Mahmoud, R.H.; Elnour, W.A. Comparative evaluation of the efficacy of ginger and orlistat on obesity management, pancreatic lipase and liver peroxisomal catalase enzyme in male albino rats. Eur. Rev. Med. Pharmaco. 2013, 17, 75-83.

8. Tsujita, T.; Sumiyoshi, M.; Han, L.-K.; Fujiwara, T.; Tsujita, J.; Okuda, H. Inhibition of lipase activities by citrus pectin. J. Nutr. Sci. Vitaminol. 2003, 49, 340-345.

9. Edashige, Y.; Murakami, N.; Tsujita, T. Inhibitory effect of pectin from the segment membrane of citrus fruits on lipase activity. J. Nutr. Sci. Vitaminol. 2008, 54, 409-415.

10. Wilcox, M.D.; Brownlee, I.A.; Richardson, J.C.; Dettmar, P.W.; Pearson, J.P. The modulation of pancreatic lipase activity by alginates. Food Chem. 2014, 146, 479-484.

11. Marounek, M.; Volek, Z.; Synytsya, A.; Čopíková, J. Effect of pectin and amidated pectin on cholesterol homeostasis and cecal metabolism in rats fed a high-cholesterol diet. Physiol. Res. 2007, $56,433-442$. 
12. Marounek, M; Volek Z.; Skřivanová E., Taubner, T.; Pebriansyah, A.; Dušková, D. Comparative study of the hypocholesterolemic and hypolipidemic activity of alginate and amidated alginate in rats. Int. J. Biol. Macromol. 2017, 105, 620-624.

13. Marounek, M.; Volek, Z.; Taubner, T.; Dušková, D.; Čermák. L. Effect of amidated alginate on faecal lipids, serum and hepatic cholesterol in rats fed diets supplemented with fat and cholesterol. Int. J. Biol. Macromol. 2019, 122, 499-502.

14. Spielman, J.; Stangl, G.I.; Eder, K. Dietary pea protein stimulates bile acid excretion and lowers hepatic cholesterol concentration in rats. J. Anim. Physiol. An. 2008, N. 92, 683-693.

15. Taubner, T.; Marounek, M.; Synytsya, A. Preparation and characterisation of amidated derivatives of alginic acid. Int. J. Biol. Macromol. 2017, 103, 202-207.

16. Taubner, T.; Marounek, M.; Synytsya, A. Preparation and characterization of hydrophobic and hydrophilic amidated derivatives of carboxymethyl chitosan and carboxymethyl beta-glucan. Int. J. Biol. Macromol. 2020, 163, 1433-1443.

17. Lindsay, H. A colorimetric estimation of reducing sugars in potatoes with 3,5-dinitrosalicylic acid. Potato Res. 1973, 16, 176-179.

18. Wang, Q.C.; Zhao, X.; Pu, J.H.; Luan, X.H. Influences of acidic reaction and hydrolytic conditions on monosaccharide composition analysis of acidic, neutral and basic polysaccharides. Carbohyd. Polym. 2016, 143, 296-300.

19. Wu, J.; Zhao, X.; Ren, L.; Xue, Y.T.; Li, C.X.; Xu, G.L.; Guan, H.S. Determination of M/G ratio of propylene glycol alginate sodium sulfate by HPLC with pre-column derivatization. Carbohyd. Polym. 2014, 104, 23-28.

20. Skřivan, M.; Marounek, M.; Engelmaierová, M.; Čermák, L.; Vlčková, J.; Skřivanová, E. Effect of dietary fat type on intestinal digestibility of fatty acids, fatty acid profiles of breast meat and abdominal fat, and mRNA expression of lipid-related genes in broiler chickens. Plos One 2018, 13, Issue 4, article no. e0196035.

21. Kobayashi, N.; Noel, E.A.; Barnes, A.; Rosenberg, J.; DiRusso, C.; Black, P.; Oyler, G.A. Rapid detection and quantification of triacylglycerol by HPLC-ELSD in Chlamydomonas reinhardtii and Chlorella strains. Lipids 2013, 48, 1035-1049. 
22. Ackroff, K.; Sclafani, A. Effects of the lipase inhibitor Orlistat on intake and preference for dietary fat in rats. Am. J. Physiol.-Reg. I. 1996, 271, R48-R54.

23. Mortensen, A.; Aguilar, F.; Crebelli, R.; Di Domenico, A.; Dosemund, B.; Frutos, M. J.; Galtier, P.; Gott, D.; Gundert-Remy, U.; Lambre, C.; Leblanc, J.C.; Lindtner, O.; Moldeus, P.; Mosesso, P.; Oskarsson, A.; Parent-Massin, D.; Stankovic, I.; Waalkens-Berendsen, I.; Wright, M.; Younes, M.; Tobback, P.; loannidou, S.; Tasiopoulou, S.; Woutersen, R.A. Re-evaluation of pectin (E440i) and amidated pectin (ET440ii) as food additives. EFSA Journal 2017, 15, article no.4866.

24. Lu, J., Yang, H., Hao, J., Wu, C.L., Liu, L., Xu, N.Y., Linhardt, R.J., Zhang, Z.Q. Impact of hydrolysis conditions on the detection of mannuronic to guluronic ratio in alginate and its derivatives. Carbohyd. Polym. 2015, 122, 180-188.

25. Sánchez-Machado, D.I.; López-Cervantes, J.; López-Hernández, J.; Paseiro-Losada, P.; Simal-Lozano, J. Determination of the uronic acid composition of seaweed dietary fibre by HPLC. Biomed. Chromatogr. 2004, 18, 90-97.

26. Marounek, M., Volek, Z., Dušková, D., Tůma, J., Taubner, T. Dose-response efficacy and long-term effect of the hypocholesterolemic effect of octadecylpectinamide in rats. Carbohyd. Polym. 2013, 97, $772-775$.

27. Tůma, J., Volek, Z., Synytsya, A., Dušková, D., Marounek, M. Hydrophobically modified celluloses as novel cholesterol-lowering polymers. BioResources 2014, 9, 4266-4273.

28. Davis, R.A., Hyde, P.M., Kuan, J.C.W., Malonemcneal, M., Archambaultschexnayder, J. Bile acid secretion by cultured rat hepatocytes - regulation by cholesterol availability. J. Biol. Chem. 1983, 258, 3661-3667. 